\title{
The Role of Physical Training in Badminton Teaching
}

\author{
Bin Xu \\ College of Foreign Languages, Northeast Dianli University, Jilin, 132012, China
}

\begin{abstract}
Badminton has been deeply loved by the people all the time. With the change in human body quality, basic equipment, and the level of science and technology, the badminton players need higher requirements in physical fitness; in addition, the movement itself needs a good fitness. Thus this paper will mainly discuss the effect of physical training in the badminton teaching, so as to strengthen the attention of the athletes' physical training.
\end{abstract}

\section{Keywords-badminton fitness training effect}

\section{INTRODUCTION}

Physical fitness refers to the comprehensive level of badminton athlete, including strength, speed, flexibility, endurance and other aspects. Although physical fitness is not as technical as badminton skill levels, it has become an important prerequisite for winning the game and standing out in the fierce competition along with the development of badminton sport. So it is necessary to pay attention to the role of physical training in badminton teaching.

\section{THE CONTENT OF BADMINTON TRAINING}

Badminton looks like a relatively easy and simple sport, but in fact it has relatively high requirements to the athlete's physical or the comprehensive ability of physical aspects. This is because the badminton has the character of fast speed, variety, its need comprehensive abilities to act as a support, i.e. motor skills of badminton require speed (strain rate and the moving speed, includes speed and speed endurance of each movement), strength (maximum power that can release) the contractive strength of muscle, and maximum strength played in a short time, endurance (namely time can last, no matter what kind of movement, all need support for endurance, as to badminton, endurance covers speed endurance, and sustain endurance), these elements are the points of badminton physical training and also the important factors of competitive ability.

\section{The FunCtion of BADMINTON PHYSICAL TRAINING}

Because in the process of movement, the badminton pay attention to running, jumping, kicking and other movements, symptoms such as collapse, asthma, etc. will emerge after a period of time if physical strength does not follow to go up. Hence it is necessary to carry out physical training teaching for badminton players. According to the analysis of physical training content, the article would analyze the function of the physical training teaching.

\section{A. The analysis on the necessity of badminton physical training teaching}

In recent years, there exists a phenomenon no matter in foreign or our country that is the athlete's skills and tactics are excellent, but still loss the game finally, the main reason is collapse and it affects the level of technology and tactics. This site also shows that nowadays people ignored the athlete's physical ability training in badminton training process, resulting in the exercise intensity is greater than the usual game. In order to improve this phenomenon, we need physical training teaching for badminton. Physical training in the badminton sport is necessary and important. First of all, to win the game, physical training teaching is the basic condition. A badminton game stays at least $50 \mathrm{~min}$, so athletes should bear long time acuteness activity, and the upper and lower body are in constant motion, if physical quality is not good, it is very difficult to bear long time continuous shot, if physical strength once not support you body, the action range will be small, the intensity will be not enough, after all it will affect the outcome of the game. Second, an excellent badminton player relies on superb skills and tactics only and ignores physical ability; he can not display his advantage fully. Because the control of height of ball point, flight direction and the intensity of the ball and so on all need physical to complete, thus only the good physical ability can control the ball in the process of the competition, and play colorful and difficult goals, he can also stand in the active position of the game, rather than a passive receiver. Finally, the tactics of badminton need physical to embody and play. Both the badminton singles and doubles should use some tactics to increase the odds of winning, lacks support from physical , even you have been taught good tactics prior to deployment, in the absence of power, tactics can not develop. In addition, if the doubles, it will affect the play of whole team and reflection of tactical skills. So no matter in the perspective of the skills, tactics or the match odds, there is a need for physical training of badminton teaching, so as to enhance the overall quality of physical fitness of athletes.

B. Analyzing the Roll badminton plays in physical
training teaching from the point of training itself

1) It is helpful to improve athlete's arms and legs power, which can improve the speed of play

Because badminton need a swing arm strength and leg jumping, the power of running, so arm strength of students can be improved after the physical training, so it makes a certain speed when the ball, and the lower limb 
can make corresponding action according to the convergence of thinking, thus can successfully complete the entire action.

2) It is helpful to develop athletes' endurance

Badminton is a sport in fast speed and short action time, generally in the process of the competition, each athlete is in a highly nervous state, in this state they also need to maintain the rapid reaction capacity, to catch and return movements constantly, so the physical training teaching can guarantee the athletes have enough physical strength to complete the corresponding technical movement in the continuous moving process.

3) It helps to develop the reaction force and sensitivity of train athletes

No matter what kind of exercise, they all require ability to act according to circumstances, as the badminton sport, less people participated in, it needs more reaction ability of flexible mind, good, and maintains accurate positioning ability in the process of rapid movement is able to power, which could complete accurate strokes and serving action and response steadfastly in the game process.

4) It helps to improve the flexibility level of the athlete body

Sports can help the body's joint to move, so does the badminton movement. After the physical training, each function, bones and muscles are spread out and the various parts of the body become coordinated, the body is also very easy to endure and overcome the intensity of the game after its adaption of greater load physical training, for

5) It helps to train athlete's willpower and mental capacity

Physical training is generally very difficult, tired, and also more boring, after long-term adherence to physical training under the guidance of teachers, students will naturally learned to insist and understand do not be afraid of hard work and perseverance will see results, thus it improved the students' psychological compressive ability, at the sane time, it cultivates students perseverance ability.

\section{PRINCIPLES AND METHODS IN BADMINTON TEACHING TRAINING}

Analysis of the effect of physical training in badminton sport based on the present stage, and people on the physical training of neglect and not paying attention, then this paper will mainly discuss how to strengthen the principles and methods of physical training teaching, in order to improve overall quality of the body of the badminton players.

\section{A. Principle in badminton physical teaching training}

1) Following the scientific principles of training

Although the physical training is aimed to improve the athletes' physical quality, but for the event, the contents and requirements of physical training is not the same, so need to follow the scientific principles of training, not blindly increase the intensity of physical training, can not be too easy to understand training, general training and specific training team body quality requirements, to the subtle relationship exists between the growth situation, understand the physical and physical training to understand the carrying capacity of strength and physical training are consistent and other factors. To be more scientific and reasonable to the athlete physical training, also can maximum the effect of physical training.

2) The training principle of differ from man to man.

This principle is based on the materialism conception, and according to the concrete analysis of specific situations, because each athlete's body function and quality are not the same, so according to the actual situation to determine each person's special physical training, but also changes with the athlete's age and the psychological quality, appropriate adjustments to the physical training is it is necessary to.

3) Training principle of commonness and individuality

For the general physical training, including running, stretching and training is every athlete must carry on training and special training is based on the gradual way slowly, first in the primary stage of physical ability training; secondly, the difficulty of medium training; and finally to the difficulty of training, so that athletes can slowly adapt and accept the physical training, also can get harvest.

Methods

\section{B. Feather ball training teaching}

1) Develop from the culture of feather ball training interested in starting

Physical training is a relatively uninteresting, but also need to consume a large amount of energy, so the first thing to let players know the importance of physical fitness training, develop training is fun, it can let the athletes in the unmanned guidance and supervision conditions, independent of physical training.

2) Develop from the physical basic skills learning of badminton

A lot of practice are based on certain theoretical knowledge as the foundation, badminton is no exception, so let the player first understand how the forehand high serve, forehand attack theory knowledge of how Gao Yuanqiu, how the backhand serve, how to pick the ball and how to serve in the process of moving, and then practice in the foundation of theoretical knowledge so as to improve the skills and tactics level.

3) The coexistence of a variety of physical training mode

The training itself is boring, but in the training process using a variety of ways to increase the training interest, such as athletes to evaluate their training results, teachers come guide, or between athletes mutual evaluation, or grouping of community physical training methods such as game, can promote the spread and effect of feather spheres training. 


\section{CONCLUSIONS}

This paper mainly discusses the physical training in badminton teaching effect, from the feather ball training on the content of the research, necessity and effect of physical training on badminton sports, feather ball training teaching can help to improve the athlete's arm and leg strength, helps athletes endurance training, help to train athletes the reaction force and sensitivity, help the athletes improve body flexibility and contributes to the cultivation of athlete's willpower and mental capacity and other aspects of the role. In view of the necessity and function, put forward the feather ball can principles and methods of teaching training, in order to further promote the feather ball training teaching.

\section{CORRESPONDING AUTHOR}

Bin $\mathrm{Xu}$. College of Foreign Languages, Northeast Dian li University, Jilin, 132012, China.

Email:34063479@qq.com.TEL:15843294007

\section{REFERENCES}

[1] Tang Weihua. Some Thinking about How to Strengthen the Physical Training of badminton athletes [J]. Journal of Huaihua University, 2010 (11): 123-125.

[2] Zhong Li. Analysis on the Function physical training plays in improving badminton athletics level [J]. Journal of Suihua University, 2006 (2): 176-177.

[3] Song Liang. Badminton Athletes Physical Training of [J]. today Keyuan, 2010 (24) : 178 